\title{
ОЦЕНКА ПРОТИВОВИРУСНОГО ПОТЕНЦИАЛА ПРОИЗВОДНЫХ ПРИРОДНЫХ СОЕДИНЕНИЙ В КАЧЕСТВЕ ИНГИБИТОРОВ РЕПЛИКАЦИИ РЕСПИРАТОРНО-СИНЦИТИАЛЬНОГО ВИРУСА
}

\author{
А.А. Штро', А.В. Галочкина', Ю.В. Николаева', К.В. Волчо',

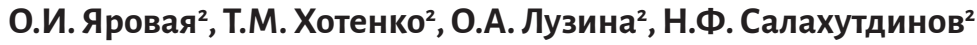 \\ ${ }^{1}$ ФГБУ «НИИ гриппа им. А.А. Смородинцева» Минздрава России, \\ 197376, Россия, Санкт-Петербург, ул. Профессора Попова, 15/17. \\ 2ФГБУН Новосибирский институт органической химии им. Н.Н. Ворожцова СО РАН, \\ 630090, Россия, Новосибирск, проспект Академика Лаврентьева, д.9.
}

DOI: 10.19163/MedChemRussia2021-2021-215_E-mail:anna.shtro@influenza.spb.ru

Респираторно-синцитиальный вирус является причиной сезонных вспышек ОРВИ среди широких слоев населения, вызывая ежегодные эпидемии. У детей старше 5 лет и взрослых инфекция протекает как легкое заболевание верхних дыхательных путей либо протекает бессимптомно, однако для младенцев в возрасте до 2 лет и пожилых людей характерно поражение не только верхних, но и нижних дыхательных путей с развитием тяжелых бронхиолитов и пневмоний, вплоть до летального исхода.

Средств для терапии респираторно-синцитиальной инфекции на территории Российской Федерации не зарегистрировано, предлагается только препарат Синагис (Паливизумаб) для профилактики данного заболевания, из-за высокой стоимости недоступный широким слоям населения. В данной работе был проведен первичный скрининг противовирусной активности в отношении респиратно-синцитиального вируса панели веществ природного происхождения, относящихся к различным химическим классам.

В ходе выполнения работы было протестировано более 100 веществ. Активность препаратов оценивали в экспериментах in vitro на клеточной культуре НЕр-2 по лечебно-профилактической схеме. Для каждого соединения высчитывали ЦТД эффективная концентрация), а также их отношение - химиотерапевтический индекс. Вещества, имеющие химиотерапевтический индекс более 10, считались перспективными.

В ходе выполнения данной работы было выявлено более 20 перспективных соединений, относящихся к природным соединениям различных структурных типов.

Работа была проведена при поддержке гранта РНФ№ 21-13-00026

«Дизайн новых агентов для борьбы с респираторно-синцитиальным вирусом у детей на основе трансформаций природных соединений» 